\title{
Does Previous Pelvic Osteotomy Compromise the Results of Periacetabular Osteotomy Surgery?
}

\author{
Jeffrey B. Stambough MD, John C. Clohisy MD, Geneva R. Baca BA, \\ Ira Zaltz MD, Robert Trousdale MD, Michael Millis MD, Daniel Sucato MD, MS, \\ Young-Jo Kim MD, PhD, Ernest Sink MD, Perry L. Schoenecker MD, \\ Rafael Sierra MD, David Podeszwa MD, Paul Beaulé MD
}

Published online: 6 January 2015

(C) The Association of Bone and Joint Surgeons (B) 2014

\begin{abstract}
Background As the Bernese periacetabular osteotomy (PAO) has grown in popularity, specific indications and the results in patients treated for those indications need to be evaluated. Currently, although many patients undergo PAO after having had prior pelvic osteotomy, there is limited information regarding the efficacy of the PAO in these patients.
\end{abstract}

The institution of one or more of the authors (JCC) has received, during the study period, funding from The International Hip Dysplasia Institute, Curing Hip Disease Fund, and the ANCHOR Research Fund.

All ICMJE Conflict of Interest Forms for authors and Clinical Orthopaedics and Related Research ${ }^{\mathbb{R}}$ editors and board members are on file with the publication and can be viewed on request.

Each author certifies that his or her institution approved the human protocol for this investigation, that all investigations were conducted in conformity with ethical principles of research, and that informed consent for participation in the study was obtained.

This work was performed at the Department of Orthopaedic Surgery, Washington University of St Louis, St Louis, MO, USA.

J. B. Stambough, J. C. Clohisy ( $₫)$, G. R. Baca,

P. L. Schoenecker

Department of Orthopaedic Surgery, Washington University

School of Medicine, 660 S Euclid Avenue, Campus Box 8233,

St Louis, MO 63110, USA

e-mail: clohisyj@wudosis.wustl.edu

I. Zaltz

Department of Orthopaedics, Beaumont Hospital, Royal Oak,

MI, USA

R. Trousdale, R. Sierra

Department of Orthopaedics, Mayo Clinic, Rochester, MN, USA

M. Millis, Y.-J. Kim

Department of Orthopaedics, Boston Children's Hospital,

Boston, MA, USA
Questions/purposes The purpose of this study was to compare the (1) early pain, function, activity, and quality of life outcomes; (2) radiographic correction; and (3) major complications and failures between patients who underwent PAO after prior pelvic reconstruction versus those who had a PAO without prior surgery.

Methods Between February 2008 and January 2012, 39 patients underwent $\mathrm{PAO}$ after prior pelvic osteotomy at one of 11 centers and were entered into a collaborative multicenter database. Of those, $34(87 \%)$ were available for followup at a mean of 2.5 years (range 1-5 years). This group was compared with a matched group of 78 subjects, of whom $71(91 \%)$ were available for followup at a similar interval. We compared clinical outcomes including UCLA activity score, SF-12, and Hip Disability and Osteoarthritis Outcome Score (HOOS); radiographic measures-anterior and lateral center-edge angle and acetabular inclination (AI) — and reoperations, major complications, and conversions to total hip arthroplasty.

D. Sucato, D. Podeszwa

Department of Orthopaedics, Texas Scottish Rite Hospital,

Dallas, TX, USA

E. Sink

Department of Orthopaedics, Hospital for Special Surgery,

New York, NY, USA

P. Beaulé

Department of Orthopaedics, University of Ottawa, Ottawa, ON, Canada 
Results Although both groups reached clinical improvement in all categorical measures, the revision PAO group demonstrated greater pain (HOOS pain, study 74 versus 85 , $\mathrm{p}=0.03 ; 95 \%$ confidence interval $[\mathrm{CI}], 18.58$ to -0.95 ) and less function (HOOS activities of daily living, study 80 versus $92, \mathrm{p}=0.002$; 95\% CI, 018.99-4.45) than the primary cohort. The revision cohort achieved a smaller average radiographic correction than in patients undergoing PAO without prior pelvic surgery. The mean correction in AI was less dramatic when directly comparing the revision and comparison groups $\left(-12^{\circ}\right.$ to $-17^{\circ}, \mathrm{p}<0.001$, SD 2.3-8.5). Although there was no difference in severe complications requiring further surgery, there were two conversions to hip arthroplasty $(\mathrm{p}=0.109 ; 95 \% \mathrm{CI}$, 0.004-2.042) in the study group.

Conclusions PAO performed after prior pelvic surgery is associated with improvements in pain, function, radiographic correction, and early complication rates, but the improvements observed at short-term followup were smaller and more variable than those seen in patients who had not undergone prior pelvic surgery. We recommend considering PAO for residual deformities after prior osteotomy to improve function and quality life but warning patients of potential ceiling effects with a second periacetabular surgery.

Level of Evidence Level III, therapeutic study.

\section{Introduction}

The Bernese periacetabular osteotomy (PAO) [11] has been popularized as a result of its ability to improve femoral head coverage and restore hip congruity while maintaining native pelvic stability through the preservation of the posterior column. Numerous studies have demonstrated its efficacy in reorienting the native, untreated dysplastic hip and delaying arthrosis with $76 \%$ to $89 \%$ reported satisfactory outcomes at mid- to long-term followup [5, 7, 19, $21,27,30,32]$. Despite the reporting of good outcomes for most patients, there is limited literature analyzing the outcomes of PAO after previous pelvic surgery.

The outcomes of the PAO surgery after prior pelvis and/ or femoral osteotomy or arthroscopic procedures have been reported in small case series [8, 10, 12, 25]. When considering only prior pelvic reconstruction, even less information exists to demonstrate the efficacy of the PAO. We therefore sought to use information collected in a multicenter database to determine whether prior pelvic osteotomies are associated with poorer outcomes after Bernese PAO.

Through the use of a multicenter repository, we sought to compare the (1) early pain, function, activity, and quality-of-life outcomes; (2) radiographic correction; and
(3) major complications and failures between patients who underwent PAO after prior pelvic reconstruction versus those who had a PAO without prior surgery.

\section{Patients and Methods}

Using the collaborative multicenter data repository from the Academic Network for Conservational Hip Outcomes Research (ANCHOR), we identified 39 patients (39 hips) who underwent PAO after prior pelvic osteotomy at seven of 11 participating centers between February 2008 and January 2012. Of those, 34 hips (87\%) were available for followup at a mean of 2.5 years (range $1-5$ years). This group was compared with a matched group of 78 subjects, of whom $71(91 \%)$ were available for followup at a similar interval. Ten patients were excluded on the basis of having "nonclassical" dysplasia. Of the remaining 39 hips, 83\% were available for evaluation with an average followup of 2.5 years (median, 2 years; range, 1-5 years). Five of 39 patients (12\%) included only achieved 1-year followup. Previous reconstructive procedures included either redirectional or reshaping osteotomies. Additional procedures performed at the time of initial pelvic osteotomy included proximal femoral osteotomy (12 cases [30\%]), hip arthroscopy (five cases [12\%]), and osteochondroplasty (one case [2\%]). The study cohort included 35 females and four males (average age, 19 years) with residual acetabular deformity after undergoing prior pelvic reconstruction. All patients included were treated with a PAO between February 2008 and July 2012 by one of 11 surgeons participating in the ANCHOR consortium. Seven of 11 participating ANCHOR site contributed patient data to this series.

A separate query of the ANCHOR PAO database was performed to identify a historical comparison group of 253 patients undergoing primary PAO from the same time period. The study group was matched to 78 subjects who underwent primary PAO for a primary diagnosis of acetabular dysplasia and were treated over the same time interval. Of these, $88 \%$ were available for followup (72 patients, 72 hips). We chose a two-to-one ratio of controls versus cases to improve the study's power. Matching was based on age, sex, and body mass index (BMI). Sex was matched exactly, individual patient age within 1 year, and BMI was within $4 \mathrm{~kg} / \mathrm{m}^{2}$ (Table 1). Patients were matched through a blinded process, regardless of outcome, by an author (JBS) who was not involved in patient care.

Patient demographics, baseline clinical scores, and radiographic measurements were all recorded. Isolated hardware removal was not included in the number of previous procedures nor was it considered an unplanned operative procedure after PAO. We used conventional 
Table 1. Demographic comparison of revision versus primary periacetabular osteotomy cohorts

\begin{tabular}{llll}
\hline Demographics & $\begin{array}{l}\text { Revision } \\
(\mathrm{N}=39)\end{array}$ & $\begin{array}{l}\text { Primary } \\
(\mathrm{N}=78)\end{array}$ & $\mathrm{p}$ value \\
\hline Average age (years) (SD) & $19.5(7)$ & $19.9(6)$ & 0.77 \\
Age range (years) & $10.9-35.4$ & $9-35.4$ & \\
Average followup (years) (SD) & $2.2(1.1)$ & $2.5(1.1)$ & 0.06 \\
Range (years) & $1.9-4.98$ & $2-5.10$ & \\
Laterality & & & 0.12 \\
Right & 15 & 43 & \\
Left & 24 & 35 & \\
Sex & & & \\
Males & 4 & 8 & 1.00 \\
Females & 35 & 70 & 1.00 \\
Average body mass & $23.3(4.8)$ & $24.0(4.3)$ & 0.77 \\
$\quad$ index (kg/m $\left.{ }^{2}\right)$ & & & \\
Range & $15.8-41.7$ & $11.7-43.0$ & \\
Race & & & \\
$\quad$ White & 34 & 70 & 0.75 \\
Black & 1 & 1 & 1.00 \\
Hispanic & 3 & 5 & 1.00 \\
Other & 1 & 2 & 1.00 \\
Family history of dysplasia & & 7 & 0.53 \\
Parent/sibling & 5 & 9 & \\
Aunt, uncle, or cousin & 2 & 5 & \\
Other & 1 & & \\
\hline
\end{tabular}

radiographic parameters that best assessed subtle morphologic findings present in hip dysplasia, including the anterior center-edge angle of Lequesne and de Seze (ACEA) [16], lateral center-edge angle of Wiberg (LCEA) [34], acetabular inclination (AI) [18, 20], and Tönnis grade for osteoarthritic changes in the hip [29]. Complete data were not available for all failed initial pelvic procedures because the majority of cases was not performed within the ANCHOR network. Both groups had $97 \%$ of patients with radiographic osteoarthritis, as categorized by a preoperative Tönnis Grade 0 or 1 (38 of 39 versus 76 of 78 , $\mathrm{p}=1.0$ ) (Table 2). No difference existed in preoperative radiographic measures for dysplasia between the groups (Table 3).

We sought to describe a comprehensive clinical health picture by measuring multiple patient-reported outcomes (PROs) [2], including the UCLA activity score [1], the SF-12 mental and physical survey [9,33], and the Hip Disability and Osteoarthritis Outcome Score (HOOS) [24]. The HOOS is a validated PRO that more precisely captures hip dysfunction in patients with and without underlying osteoarthritis $[13,14]$. PROs indicated no difference between groups preoperatively (HOOS subscales [Table 4]: symptoms $p=0.96$, pain $\mathrm{p}=0.83$, activities of daily living 0.769 , and quality of life 0.879); SF-12 physical [Table 5]: $\mathrm{p}=0.93$; UCLA activity
Table 2. Radiographic preoperative differences between revision and primary periacetabular osteotomy cohorts

\begin{tabular}{lll}
\hline $\begin{array}{l}\text { Tönnis osteoarthritis grade } \\
\text { preoperatively }\end{array}$ & $\begin{array}{l}\text { Revision } \\
(\mathrm{N}=39)\end{array}$ & $\begin{array}{l}\text { Primary } \\
(\mathrm{N}=78)\end{array}$ \\
\hline 0 & 15 & 38 \\
1 & 23 & 38 \\
2 & 1 & 2 \\
3 & 0 & 0 \\
\hline
\end{tabular}

[Table 5], $\mathrm{p}=0.76$ ). We adopted the minimal clinically important difference (MCID) thresholds established by Kemp et al. [13] for the HOOS in an arthroscopic hip surgery group of similar age given the similarities in disease presentation.

Every study patient carried a primary diagnosis of acetabular dysplasia. Those with nonclassical dysplasia were excluded from the study, which included Charcot-MarieTooth (three), cerebral palsy (three), congenitally short femur (two), and Perthes deformities (two). Twenty-six additional procedures performed at the time of initial pelvic osteotomy included five arthroscopies and sixteen proximal femoral osteotomies.

Groups had few differences in hip morphology preoperatively as indicated by conventional radiographic parameters. The study group had greater coverage (LCEA $\mathrm{p}=0.042$; $95 \%$ confidence interval [CI], 0.1-11; mean $12^{\circ}$ [ -32 to 50], SD 13 versus 7 [ -29 to 24], SD 12), yet no other pentameters set this group apart from those undergoing primary PAO (AI $\mathrm{p}=0.322$, mean $21^{\circ}$ versus $23^{\circ} ;$ ACEA $\mathrm{p}=0.051$, mean $12^{\circ}$ versus $4^{\circ}$ ).

General indications for PAO surgery included hip pain, radiographic evidence of acetabular dysplasia or retroversion, acetabular deformity that was correctible through the use of a PAO, and adequate hip ROM with passive flexion to at least $90^{\circ}$. Patients were not considered good surgical candidates if they had previous reconstructive hip surgery resulting in a severely incongruent joint or if they had severe limitation in hip motion.

We collected all major complications, including Grade III and IV according to the Clavien-Dindo classification scheme outlined by Sink et al. [26]. There were no deaths (Grade V) in either cohort. The most common associated procedure performed in the revision group was femoral head/neck osteochondroplasty in (18 cases [46\%]; Table 6). Altogether, the revision cohort had a similar number of procedures being performed at the time of PAO (26 of 39 versus 55 of 78 , $\mathrm{p}=0.096$ ).

A two-tailed t-test was used to assess continuous variables including age, followup duration, BMI, PROs, and radiographic correction within and between the study and comparison groups. Categorical variables including race, family history, surgical complications, complications, and 
Table 3. Radiographic correction achieved between the study group (S) after revision PAO and the comparison group (C) after initial periacetabular osteotomy*

\begin{tabular}{|c|c|c|c|c|c|c|c|c|c|c|c|}
\hline \multirow[t]{2}{*}{ Measure } & \multicolumn{4}{|c|}{ Preoperative measures } & \multicolumn{4}{|c|}{ Postoperative measures } & \multirow[t]{2}{*}{$95 \% \mathrm{CI}$} & \multirow[t]{2}{*}{$\mathrm{p}$ value } & \multirow{2}{*}{$\begin{array}{l}\text { Pre/post } \\
\text { difference } \\
\text { Mean }\end{array}$} \\
\hline & Number & Mean & Range & $\mathrm{SD}$ & Number & Mean & Range & SD & & & \\
\hline LCEA-S & 48 & 10 & $(-29)$ to 50 & 15 & 36 & 31 & $(-1)$ to 48 & 9 & 14 to $23^{\neq}$ & $<0.001^{\neq}$ & 19 \\
\hline LCEA-C & 98 & 7 & $(-30)$ to 50 & 13 & 86 & 30 & $(-0.9)-52$ & 8 & 19 to $25^{\neq}$ & $<0.001^{\neq}$ & 22 \\
\hline $\mathrm{p}$ value* & $0.191^{\dagger}$ & & & & $0.648^{\dagger}$ & & & & & & $0.209^{\dagger}$ \\
\hline $95 \% \mathrm{CI}$ & -2.6 to $4^{\dagger}$ & & & & & & & & & -3 to $4^{\dagger}$ & -2 to $8^{\dagger}$ \\
\hline AI-S & 48 & 21 & $(-15)$ to 49 & 14 & 35 & 9 & 0.7 to 29 & 6 & -16 to $-7^{\neq}$ & $<0.001^{\neq}$ & -12 \\
\hline AI-C & 98 & 22 & $0-44$ & 9 & 86 & 5 & $(-13)$ to 22 & 6 & -197 to $-15^{\neq}$ & $<0.001^{\neq}$ & -17 \\
\hline $\mathrm{p}$ value* & $0.563^{\dagger}$ & & & & $<0.001^{\dagger}$ & & & & & & $0.025^{\dagger}$ \\
\hline $95 \% \mathrm{CI}$ & 2 to $66^{\dagger}$ & & & & & & & & & 2 to $7^{\dagger}$ & 0.603 to 8.65 \\
\hline ACEA-S & 39 & 10 & $(-28)$ to 60 & 19 & 29 & 24 & $(-2)$ to 53 & 13 & 6 to 20 & $0.0014^{\neq}$ & 13 \\
\hline ACEA-C & 89 & 4 & $(-50)$ to 46.4 & 15 & 79 & 32 & 2 to 62 & 12 & 21 to $30^{\neq}$ & $<0.001^{\neq}$ & 25 \\
\hline $\mathrm{p}$ value* & $0.112^{\dagger}$ & & & & $0.004^{\dagger}$ & & & & & & $<0.001^{\dagger}$ \\
\hline $95 \% \mathrm{CI}$ & -1 to $12^{\dagger}$ & & & & & & & & & -13 to $-3^{\dagger}$ & -21 to $-3^{\dagger}$ \\
\hline
\end{tabular}

* Measurements studied include lateral center-edge angle (LCEA), acetabular inclination (AI), and anterior center-edge angle (ACEA); ${ }^{\dagger} \mathrm{p}$ value and CI of Student's t-test between groups; ${ }^{*} \mathrm{p}$ value and CI by Student's t-test for pre- and postmeasures within group; PAO = periacetabular osteotomy; $\mathrm{CI}=$ confidence interval; $-\mathrm{S}=$ study group (PAO after prior pelvic surgery); $-\mathrm{C}=$ control group (primary PAO).

Table 4. Pre- and postoperative comparisons of the pain, stiffness, physical, and total subscores of the HOOS questionnaire in the revision (study) versus primary (comparison) periacetabular osteotomy setting*

\begin{tabular}{|c|c|c|c|c|c|c|c|c|}
\hline Group & HOOS & Preoperative & Range & Postoperative & Range & $\Delta$ & $\mathrm{p}$ value & MCID \\
\hline Study & Symptom & 61 & $20-100$ & 74 & $15-100$ & 12 & 0.002 & 9 \\
\hline \multirow[t]{2}{*}{ Comparison } & Symptom & 60 & $5-95$ & 80 & $50-100$ & 20 & $<0.001$ & \\
\hline & $\mathrm{p}$ value & 0.837 & & 0.081 & & 0.111 & & \\
\hline Study & Pain & 58 & $23-100$ & 77 & $10-100$ & 20 & $<0.001$ & 9 \\
\hline \multirow[t]{2}{*}{ Comparison } & Pain & 56 & $0-100$ & 85 & $38-100$ & 29 & $<0.001$ & \\
\hline & $\mathrm{p}$ value & 0.621 & & 0.031 & & 0.073 & & \\
\hline Study & $\mathrm{ADL}$ & 70 & $12-100$ & 83 & $15-100$ & 14 & 0.004 & 6 \\
\hline \multirow[t]{2}{*}{ Comparison } & ADL & 67 & $0-100$ & 92 & $51-100$ & 23 & $<0.001$ & \\
\hline & $\mathrm{p}$ value & 0.598 & & 0.035 & & 0.047 & & \\
\hline Study & $\mathrm{S} \& \mathrm{R}$ & 53 & $0-100$ & 73 & $0-100$ & 18 & 0.005 & 10 \\
\hline \multirow[t]{2}{*}{ Comparison } & $\mathrm{S} \& \mathrm{R}$ & 45 & $0-100$ & 78 & $13-100$ & 33 & $<0.001$ & \\
\hline & $\mathrm{p}$ value & 0.059 & & 0.2511 & & 0.027 & & \\
\hline Study & QOL & 39 & $0-100$ & 63 & $0-100$ & 25 & $<0.001$ & 11 \\
\hline \multirow[t]{2}{*}{ Comparison } & QOL & 36 & $0-100$ & 70 & $25-100$ & 34 & $<0.001$ & \\
\hline & $\mathrm{p}$ value & 0.484 & & 0.159 & & 0.118 & & \\
\hline
\end{tabular}

* Statistical relationships of significance ( $\mathrm{p}$ values) are analyzed within and between cohorts. Minimal clinically important differences (MCIDs) are listed as a reference; HOOS = Hip Disability and Osteoarthritis Outcome Score, which consists of five subcategory ratings: symptoms, pain, activities of daily living (ADL), sports and recreation (S\&R), and quality of life (QOL).

failures were assessed with either chi-square analysis or Fisher's exact test. A post hoc power analysis was conducted based on continuous response variables from independent control and experimental subjects predetermined as our primary outcome measure. In a previous study the response within each subject group was normally distributed with a SD of 13 [24]. If the true difference in the experimental and control means is 9.1, we would have needed to study 25 experimental subjects and 50 control subjects to be able to reject the null hypothesis that the population means of the experimental and control groups are equal with probability (power) 0.8 . We chose to match to the experimental subjects in a 2:1 manner to better adjust for the additional outcome variables measured. The Type I 
Table 5. Pre- and postoperative comparisons of patient-reported outcome measures in the revision (study) versus primary (comparison) periacetabular osteotomy setting*

\begin{tabular}{llllllll}
\hline Group & Outcome & Preoperative & Range & Postoperative & Range & $\Delta$ & p value (within group) \\
\hline Study & mHHS & 62 & $20-100$ & 78 & $22-100$ & 24 & $<0.001$ \\
Comparison & mHHS & 59 & $3-100$ & 86 & $54-100$ & 26 & $<0.001$ \\
& p value (between groups) & 0.374 & & 0.016 & & 0.060 & \\
Study & SF-12 Physical & 45 & $18-74$ & 51 & $17-66$ & 8 & $<0.001$ \\
Comparison & SF-12 Physical & 40 & $14-59$ & 49 & $28-63$ & 9 & $<0.001$ \\
& p value & 0.001 & & 0.144 & & 0.069 & -0.2 \\
Study & UCLA & 6.9 & $3-10$ & 7.0 & $2-10$ & 0.756 \\
Comparison & UCLA & 7.2 & $2-10$ & 7.7 & $3-10$ & 0.4 & 0.164 \\
& p value & 0.498 & & 0.112 & & 0.307 &
\end{tabular}

* Statistical relationships of significance ( $\mathrm{p}$ values) are analyzed within and between cohorts; mHHS = modified Harris hip score.

Table 6. Additional procedures performed at the time of revision and primary periacetabular osteotomy

\begin{tabular}{lcll}
\hline Associated procedures & $\begin{array}{l}\text { Revision } \\
(\mathrm{n}=39)\end{array}$ & $\begin{array}{l}\text { Primary } \\
(\mathrm{n}=78)\end{array}$ & $\mathrm{p}$ value \\
\hline Associated procedures & 26 & 55 & 0.096 \\
Femoral head/neck osteochondroplasty & 18 & 29 & 0.424 \\
Arthroscopy & 2 & 15 & 0.051 \\
Labral refixation/repair & 3 & 6 & 1.00 \\
Intertrochanteric osteotomy & 1 & 2 & 1.00 \\
Labral resection & 1 & 3 & 1.00 \\
Psoas lengthening & 1 & 0 & 0.333 \\
\hline
\end{tabular}

error probability associated with this test of the null hypothesis is 0.05 .

\section{Results}

At an average 2.5-year followup (range, 1-5 years), the revision PAO cohort demonstrated greater pain (HOOS pain, study 74 versus $85, \mathrm{p}=0.03 ; 95 \% \mathrm{CI}, 18.58$ to -0.95 ) and less function (HOOS activities of daily living, study 80 versus $92, \mathrm{p}=0.002 ; 95 \%$ CI, 18.99-4.45). Both groups showed substantial improvement in function, activity, pain, and quality of life as measured by the SF-12, UCLA activity score (Table 5), and HOOS subscales (Table 4). The mean improvement in PRO scores experienced by hips in the revision cohort included 8 points in SF-12 function ( $\mathrm{p}<0.001$, SD 11; 95\% CI, 4.2-11.4), 0.2 in UCLA activity $(\mathrm{p}=0.1), 11$ in HOOS symptoms $(\mathrm{p}=0.007$, SD $23 ; 95 \%$ CI, 3.38-20.07), 20 in HOOS pain $(\mathrm{p}<0.001$, SD 15; 95\% CI, 9.86-29.6), 24 in HOOS activities of daily living $(\mathrm{p}=0.02$, SD $24 ; 95 \%$ CI, 2.0222.7), 17 in HOOS sports and recreation $(\mathrm{p}=0.024$, SD 30 ; $95 \% \mathrm{CI}, 2.3-31$ ), and 25 in HOOS quality of life
( $\mathrm{p}<0.001$, SD 29; 95\% CI, 13.19-36.4). In contrast, those who underwent primary PAO had greater mean improvements in PROs. Mean improvement of SF-12 was 9 ( $\mathrm{p}<$ 0.001, SD 9; 95\% CI, 6.3-11.7), 0.4 for UCLA $(\mathrm{p}=0.954), 20$ for HOOS symptoms $(\mathrm{p}<0.001$, SD 16; 95\% CI, 12.51-23.72), 28 for HOOS pain ( $<0.001$, SD 27; 95\% CI, 21.6-33.3), 23 for HOOS activities of daily living ( $\mathrm{p}<0.001$, SD 10; 95\% CI, 16-28.9), 31 for HOOS sports and recreation $(\mathrm{p}<0.001$, SD $21 ; 95 \% \mathrm{CI}, 23.4$ $39.1)$, and 32 for HOOS quality of life ( $<<0.001$, SD 22; 95\% CI, 25-38.1). The amount of clinical improvement for revision PAOs surpassed the thresholds for a MCID in all HOOS subcategories (Table 4).

The radiographic correction achieved was smaller in patients who had undergone prior pelvic osteotomy surgery than in patients undergoing $\mathrm{PAO}$ without prior pelvic surgery. With revision PAOs, the mean correction attained was $19^{\circ}$ for LCEA $\left(\mathrm{p}<0.001\right.$, SD $\left.10^{\circ} ; 95 \% \mathrm{CI}, 14-24\right)$, $13^{\circ}$ for ACEA $\left(\mathrm{p}=0.014\right.$, SD $\left.12^{\circ} ; 95 \% \mathrm{CI}, 5-20\right)$, and $-12^{\circ}$ for $\mathrm{AI}\left(\mathrm{p}<0.001, \mathrm{SD} 9^{\circ} ; 95 \% \mathrm{CI},-20\right.$ to -15$)$ (Table 3). In comparison, the mean correction attained in the primary cohort was $22^{\circ}$ in LCEA $\left(\mathrm{p}<0.001\right.$, SD $10^{\circ}$; 95\% CI, 20-26), $-17^{\circ}$ for AI (p < 0.001, SD 6 ; 95\% CI, -16 to -6 ), and $24^{\circ}$ for ACEA ( $p<0.001$, SD $12^{\circ}$; $95 \%$ CI, 19-29). The mean correction in AI was less dramatic when directly comparing the revision and comparison groups $\left(-12^{\circ}\right.$ to $-17^{\circ}, \mathrm{p}<0.001$, SD 2.3-8.5).

Two patients in the study cohort underwent early conversion to THA at 12 and 28 months after revision PAO as a result of symptomatic progression from Tönnis Grade 1 to 2 osteoarthritis, whereas no patients in the comparison group have undergone THA $(p=0.109)$. We found no difference between groups when considering major complications $(\mathrm{p}=1.00)$. Additionally, there was no difference in complications resulting in unplanned reoperation $(p=0.104)$ (Table 7). In the study cohort, three additional surgical indications and procedures included a posterior column 
Table 7. Major and minor complications in revision and primary periacetabular osteotomy groups

\begin{tabular}{llll}
\hline Adverse events & Revision & Primary & $\mathrm{p}$ value \\
\hline Major complications & 3 & 6 & 1.00 \\
Major nerve palsy & 1 & 2 & 1.00 \\
Impingement & 1 & 1 & 1.00 \\
Fracture & 1 & 1 & 1.00 \\
HO (Grade III/IV) & 0 & 1 & 1.00 \\
DVT & 0 & 1 & 1.00 \\
& & & 1.00 \\
Reoperations & 3 & 1 & 0.104 \\
Hip arthroscopy + osteochondroplasty & 2 & 1 & 1.00 \\
Posterior column ORIF & 1 & 0 & 0.333 \\
THA conversion & 2 & 0 & 0.109 \\
\hline
\end{tabular}

$\mathrm{HO}=$ heterotopic $\quad$ ossification; $\quad$ DVT $=$ deep vein thrombosis; ORIF $=$ open reduction and internal fixation .

fracture treated by open reduction and internal fixation and two hip arthroscopies to address resultant femoroacetabular impingement (FAI) with femoral head/neck osteochondroplasties and acetabular rim reshaping compared with one unplanned procedure in the control group for resultant FAI treated by arthroscopy, osteoplasty, and capsular tightening. The incidence of heterotopic ossification (HO) did not differ between groups $(\mathrm{p}=1.0)$ and was asymptomatic in all but one case. In the comparison cohort, one subject developed Grade IV HO, defined as radiographic ankylosis by Brooker et al.'s grading scale [4], but opted for nonsurgical management as a result of minimal symptoms.

\section{Discussion}

The PAO has become a well-accepted reconstructive procedure for the treatment of symptomatic acetabular dysplasia associated with complex deformities [6, 17]. Technical challenges in a previously operated hip include abnormal intermuscular planes resulting from scarring, distortion of the bony anatomy from prior osteotomies, and impaired muscle function from chronic disease and/or prior surgery. Sparse data currently exist regarding revision PAO surgery. De La Rocha et al. [10] demonstrated gait abnormalities at 1year followup (mean, 1.1 years; range, $0.9-1.9$ years) in 13 patients who had 15 revision proceduresowing to decreased hip flexion and abduction strength compared with a first-time PAO cohort. Czubak and colleagues [8] noted improvements in pain but decreased hip flexion in 10 adult patients who underwent PAO years after a prior Chiari, shelf, or Dega osteotomy. Likewise, Mayo et al. [22] reported that of the nine of 10 patients with prior pelvic osteotomies who underwent a PAO at an average of 30 years, all achieved improvement in every form of measured radiographic coverage correction and had similar Harris hip scores as a control PAO group. To evaluate the efficacy of PAO surgery in the setting of prior pelvic surgery, we compared clinical outcomes, radiographic parameters, and complications/failures of PAO surgery in the setting of previous pelvic reconstruction versus PAO surgery without previous procedures. Our data indicate that PAO after prior pelvic surgery is safe and is associated with appreciable clinical and radiographic improvements. Nevertheless, these improvements are less profound when compared with primary PAO surgery.

Limitations of our study include its retrospective nature, yet a prospective investigation on this topic is difficult as a result of the uncommon nature of revision PAO surgery. Second, there may be slight differences among surgeon indications, operative methods, and rehabilitation protocols with cases taken from different sites. Nevertheless, the relatively low incidence of such revision cases makes multicenter data collection attractive even with slight variations in treatment protocols. A third drawback of the study relates to the inherent limitations of determining dysplasia measurements through radiographs [31]. To combat this issue, we had a research assistant who has been measuring young adult hips for greater than 10 years perform all of the measurements pre- and postoperatively [15, 23]. Finally, a fourth limitation of the study is the shortterm followup and the loss of five patients between the 1and 2-year time points. This is problematic because these missed data points do not allow us to fully capture subsequent problems or surgeries these hips may have encountered. Although longer followup studies are needed, our results capture improvements in pain and function accomplished by a revision PAO and can be used for patient education and setting expectations for how one will recover by 1 year and beyond. We believe that a less dramatic radiographic correction will not necessarily lead to earlier conversion to hip arthroplasty because these patients often have less high activity demands. It is our intent in the future to compare the results of revision PAO surgery with a matched cohort of patients who have failed PAO and gone on to convert to a THA.

The amount of radiographic correction achieved in our studies was similar to that of others reported in the literature. Czubak et al. [8] found that in their cohort of 43 hips, the mean ACEA improved from $-10^{\circ}$ to $35^{\circ}$. De La Rocha et al. [10] reported a change in LCEA from $1.9^{\circ}$ to $26.2^{\circ}$, Tönnis angle from $25.3^{\circ}$ to $10.1^{\circ}$, and ACEA from $-3^{\circ}$ to $20.1^{\circ}$. Mayo et al. [22] calculated an increased LCEA from $5^{\circ}$ to $29^{\circ}$, improved $\mathrm{AI}$ of $24^{\circ}$ to $6^{\circ}$, and more anterior coverage with an ACEA of $3^{\circ}$ to $24^{\circ}$. These results are aligned both in magnitude of improvement and final coverage angles with the results we detail (Table 3). It is plausible that the less profound ACEA correction we 
achieved in our cohort was the result of surgeons' preferred surgical approach, because ours did not perform an extended Smith-Peterson approach as used by Czubak et al. [8]. As for the difference between the cohorts, that can be explained by the nature of the revision PAO. It is worth noting, however, that patients with dysplastic hips undergoing primary PAO had greater average improvements in all PROs. This finding points toward a potential ceiling effect with revision PAO, perhaps as a result of preexisting altered anatomy, intraarticular disease, muscle dysfunction, and possible limitations in deformity correction inherent to revision surgery. Likewise, the fact that the revision cohort started at a higher baseline level of pain and function could suggest that the initial PAO provided some symptomatic improvement, although it left the study cohort group with residual deformities. As a result of the variable deformity encountered in the revision setting, ranging from radically insufficient coverage to excessive overcoverage, the amount of correction one aims to achieve varies. Furthermore, the surgeon relies heavily on the intraoperative examination to check for impingement and hip stability, which may have been exacerbated from the initial procedures. It is our impression that these revision cases inherently are more complex and more commonly require additional procedures.

Overall, the $7 \%$ frequency of major complications in our revision cohort was slightly greater than the $4 \%$ cited in the literature for primary PAO surgery [28]. The proportion of patients who underwent conversion to THA (5\% [two of 39]) is comparable to the reported failure rates for primary PAOs [3, 5, 21, 32] but was more than we observed for our comparison group $(0 \%)$. Although there was a low incidence of early failures in the study group, there may be an even greater risk for early failure in the revision setting that our study was unable to detect as a result of being underpowered and/or the short-term followup. Thus, hips with previous procedures and more chronic symptoms may have an increased risk for early failure and conversion to THA.

Failed pelvic surgery for hip dysplasia can result in ongoing pain, dysfunction, and altered anatomic relationships that are difficult to treat. Our data suggest that residual acetabular deformities can be corrected in patients who have undergone previous reconstructive pelvic surgery. Furthermore, these data indicate that clinical improvements in pain and function are achieved for most patients. However, the amount of clinical and radiographic improvement is limited in the revision scenario perhaps in part resulting from scarring, muscle dysfunction, chronicity of symptoms, and more advanced intraarticular disease. Our short-term data demonstrate acceptable safety and efficacy profiles for revision PAO surgery with low complication rates and an acceptably small risk of total hip conversion. We assert that PAO is a viable option in treating residual deformity after previous pelvic surgery. Our data should influence patient and surgeon expectations and treatment decision-making because the clinical outcomes of such procedures may not be as predictable or as profound as first-time pelvic osteotomy surgery.

\section{References}

1. Amstutz HC, Thomas BJ, Jinnah R, Kim W, Grogan T, Yale C. Treatment of primary osteoarthritis of the hip. A comparison of total joint and surface replacement arthroplasty. J Bone Joint Surg Am. 1984;66:228-241.

2. Bellamy N, Buchanan WW. A preliminary evaluation of the dimensionality and clinical importance of pain and disability in osteoarthritis of the hip and knee. Clin Rheumatol. 1986;5:231-241.

3. Biedermann R, Donnan L, Gabriel A, Wachter R, Krismer M, Behensky H. Complications and patient satisfaction after periacetabular pelvic osteotomy. Int Orthop. 2008;32:611-617.

4. Brooker AF, Bowerman JW, Robinson RA, Riley LH Jr. Ectopic ossification following total hip replacement. Incidence and a method of classification. J Bone Joint Surg Am. 1973;55:1629-1632.

5. Clohisy JC, Barrett SE, Gordon JE, Delgado ED, Schoenecker PL. Periacetabular osteotomy for the treatment of severe acetabular dysplasia. J Bone Joint Surg Am. 2005;87:254-259.

6. Clohisy JC, Ross JR, North JD, Nepple JJ, Schoenecker PL. What are the factors associated with acetabular correction in Perthes-like hip deformities? Clin Orthop Relat Res. 2012;470:3439-3445.

7. Crockarell J Jr, Trousdale RT, Cabanela ME, Berry DJ. Early experience and results with the periacetabular osteotomy. The Mayo Clinic experience. Clin Orthop Relat Res. 1999;363:45-53.

8. Czubak JB, Tyrakowski M, Pietrzak S. Periacetabular Ganz osteotomy in the treatment of hip dysplasia in adolescent and young adults with previous hip surgery in childhood. J Bone Joint Surg Br. 2009;91:29-29.

9. Davidson D, Yen Y-M, Jette AM, Olarsch S, Kim Y-J. Responsiveness of the SF-36 and WOMAC following periacetabular osteotomy for acetabular dysplasia. J Bone Joint Surg Am. 2011;93:2214-2218.

10. De La Rocha A, Sucato DJ, Tulchin K, Podeszwa DA. Treatment of adolescents with a periacetabular osteotomy after previous pelvic surgery. Clin Orthop Relat Res. 2012;470:2583-2590.

11. Ganz R, Klaue K, Vinh TS, Mast JW. A new periacetabular osteotomy for the treatment of hip dysplasias. Technique and preliminary results. Clin Orthop Relat Res. 1988;232:26-36.

12. Kain MSH, Novais EN, Vallim C, Millis MB, Kim Y-J. Periacetabular osteotomy after failed hip arthroscopy for labral tears in patients with acetabular dysplasia. J Bone Joint Surg Am. 2011;93(Suppl 2):57-61.

13. Kemp JL, Collins NJ, Roos EM, Crossley KM. Psychometric properties of patient-reported outcome measures for hip arthroscopic surgery. Am J Sports Med. 2013;41:2065-2073.

14. Klässbo M, Larsson E, Mannevik E. Hip disability and osteoarthritis outcome score. An extension of the Western Ontario and McMaster Universities Osteoarthritis Index. Scand J Rheumatol. 2003;32:46-51.

15. Lehmann CL, Nepple JJ, Baca G, Schoenecker PL, Clohisy JC. Do fluoroscopy and postoperative radiographs correlate for periacetabular osteotomy corrections? Clin Orthop Relat Res. 2012;470:3508-3514.

16. Lequesne M, de Seze. [False profile of the pelvis. A new radiographic incidence for the study of the hip. Its use in dysplasias and different coxopathies] [in French]. Rev Rhum Mal Ostéoarticul. 1961;28:643-652. 
17. Leunig M, Ganz R. Evolution of technique and indications for the Bernese periacetabular osteotomy. Bull NYU Hosp Jt Dis. 2011;69(Suppl 1):S42-46.

18. Massie WK, Howorth MB. Congenital dislocation of the hip. Part I. Method of grading results. J Bone Joint Surg Am. 1950;32:519-531.

19. Matheney T, Kim Y-J, Zurakowski D, Matero C, Millis M. Intermediate to long-term results following the bernese periacetabular osteotomy and predictors of clinical outcome: surgical technique. J Bone Joint Surg Am. 2010;92(Suppl 1):115-129.

20. Matsui M, Masuhara K, Nakata K, Nishii T, Sugano N, Ochi T. Early deterioration after modified rotational acetabular osteotomy for the dysplastic hip. J Bone Joint Surg Br. 1997;79:220224.

21. Matta JM, Stover MD, Siebenrock K. Periacetabular osteotomy through the Smith-Petersen approach. Clin Orthop Relat Res. 1999;363:21-32.

22. Mayo KA, Trumble SJ, Mast JW. Results of periacetabular osteotomy in patients with previous surgery for hip dysplasia. Clin Orthop Relat Res. 1999;363:73-80.

23. Nassif NA, Schoenecker PL, Thorsness R, Clohisy JC. Periacetabular osteotomy and combined femoral head-neck junction osteochondroplasty: a minimum two-year follow-up cohort study. J Bone Joint Surg Am. 2012;94:1959-66.

24. Nilsdotter AK, Lohmander LS, Klässbo M, Roos EM. Hip disability and osteoarthritis outcome score (HOOS) — validity and responsiveness in total hip replacement. BMC Musculoskelet Disord. 2003;4:10.

25. Polkowski GG, Novais EN, Kim Y-J, Millis MB, Schoenecker PL, Clohisy JC. Does previous reconstructive surgery influence functional improvement and deformity correction after periacetabular osteotomy? Clin Orthop Relat. Res. 2012;470:516-524.

26. Sink EL, Leunig M, Zaltz I, Gilbert JC, Clohisy J, Academic Network for Conservational Hip Outcomes Research Group. Reliability of a complication classification system for orthopaedic surgery. Clin Orthop Relat Res. 2012;470:2220-2226.

27. Steppacher SD, Tannast M, Ganz R, Siebenrock KA. Mean 20year followup of Bernese periacetabular osteotomy. Clin Orthop Relat Res. 2008;466:1633-1644.

28. Thawrani D, Sucato DJ, Podeszwa DA, DeLaRocha A. Complications associated with the Bernese periacetabular osteotomy for hip dysplasia in adolescents. J Bone Joint Surg Am. 2010;92:1707-1714.

29. Tönnis D. Congenital Dysplasia and Dislocation of the Hip in Children and Adults. Berlin, Germany: Springer; 1987.

30. Troelsen A, Elmengaard B, Søballe K. Medium-term outcome of periacetabular osteotomy and predictors of conversion to total hip replacement. J Bone Joint Surg Am. 2009;91:2169-2179.

31. Troelsen A, Romer L, Kring S, Elmengaard B, Soballe K. Assessment of hip dyslpasia and osteoarthritis: variability of different methods. Acta Radiol. 2010;51:187-193.

32. Trumble SJ, Mayo KA, Mast JW. The periacetabular osteotomy. Minimum 2 year followup in more than 100 hips. Clin Orthop Relat Res. 1999;363:54-63.

33. Ware J Jr, Kosinski M, Keller SD. A 12-item Short-Form Health Survey: construction of scales and preliminary tests of reliability and validity. Med Care. 1996;34:220-233.

34. Wiberg G. Studies on dysplastic acetabular and congenital subluxation of the hip joint. With special reference to the complication of osteoarthritis. Parts HV. Acta Chir Scand Suppl. 1939;58:7-38. 